4if

TRANS $\cdot$ núm. I9.2 2015

NOTAS $\cdot 265-276$
Este artículo trata del problema que plantea en las traducciones al castellano la elección de un modelo de lengua susceptible de generar incomprensión o incomodidad en diferentes lugares del ámbito hispánico. Un problema que se duplica cuando la obra objeto de la traducción recurre de modo más o menos extensivo a la variación lingüística. En esos casos la "suspensión de la incredulidad" sobre la que se basa el pacto lector exige por parte del traductor soluciones imaginativas.

Junto con algunas reflexiones generales acerca de la traducción, se presentan a continuación ejemplos extraídos de la traducción de Breve diccionario inglés-chino para enamorados de Xiaolu Guo y Todo un hombre de Tom Wolfe (dos obras que hacen un uso extensivo de la distorsión del lenguaje estándar) con el objeto de ilustrar algunas formas en que la dificultad puede resolverse en términos literarios, esquivando el equívoco paradigma de la fidelidad y la equivalencia. Se presentan asimismo algunas reacciones de críticos y lectores comunes a semejante propuesta.

PALABRAS CLAVE variación lingüística, suspensión de la incredulidad, crítica de traducciones, Tom Wolfe, Xiaolu Guo

\title{
De espejos y máscaras. Una propuesta para la traducción de los lenguajes «rotos»
}

\section{On Mirrors and Masks. A Proposal for the Translation of Broken Languages}

This article deals with the challenge posed in the translation into Spanish by the translator's choice of a certain linguistic model that could cause misunderstandings or awkwardness in some Spanish-speaking areas. The challenge is twofold when the original makes a more or less extensive use of linguistic variation. In such cases "suspension of disbelief" - upon which the reader's contract is based - calls for imaginative solutions on the part of the translator.

Along with general reflections on translation, some examples from the

JuAn Gabriel López Guix

Universidad Autónoma de Barcelona
Spanish translation of Xiaolu Guo's A Concise Chinese-English Dictionary for Lovers and Tom Wolfe's A Man in Full (two works that rely on an extensive use of distorted language) are offered in order to show how this kind of difficulty can be addressed in literary terms, avoiding the misleading paradigm of fidelity and equivalence. Some reactions to this approach by ordinary readers and professional reviewers are also offered.

KEY WORDS linguistic variation, suspension of disbelief, translation criticism, Tom Wolfe, Xiaolu Guo 


\section{NUESTRA IDEA DE LA TRADUCCIÓN}

En un texto publicado en la sección «El Trujamán» del Centro Virtual Cervantes, Juan Jesús Zaro mencionaba citando a Michael Heim una posible estrategia para hallar solución al problema de la traducción de las variantes lingüísticas (Zaro, 20I4). Heim, en un artículo sobre el modo de abordar ese problema por parte del traductor literario al inglés, propone inventar un lenguaje convencional compuesto por elementos procedentes de múltiples orígenes, sin correlato en el habla real de los hablantes y cuya función sería mostrar simplemente un alejamiento con el lenguaje estándar. Siguiendo esa línea, Zaro imagina la creación de un «español midatlántico» que, para uso de los traductores, combine rasgos de los territorios hispanohablantes. El problema resulta aún más complejo si pensamos que a la variación diatópica puede añadirse la variación diastrática.

En relación con el problema general de la variación diatópica, algunas editoriales españolas exploraron en los noventa la opción «mesoatlántica», y así Tusquets, por ejemplo, estudió la posibilidad de establecer un glosario de preferencias léxicas lo más inclusivas posibles. Otras editoriales, como por ejemplo Ediciones B, han evitado tradicionalmente el uso de ciertos vocables considerados ofensivos o vulgares en algunos países latinoamericanos. El sector también se ha decantado por las dobles o triples versiones en los casos de libros en los que se preveían grandes ventas. Son famosos algunos casos como el de la novela Las cenizas de Ángela de Frank McCourt, publicada por la editorial colombiana Norma en 1997 en una traducción firmada por Carlos José Restrepo y editada al mismo tiempo en España por Maeva en una versión de Alejandro Pareja; o como en el 2004 las tres versiones de Harry Potter y la Orden del Fénix de J. K. Rowling: la española de Gemma Rovira y las adaptaciones de María José Rodríguez Murguiondo (para Argentina, Chile, Paraguay Uruguay) y de Myriam Rudoy (para México y el resto de países americanos).

Cuando el lenguaje de la obra ofrece rasgos que lo alejan del uso estándar, las dificultades se duplican. Entre los traductores individuales, por su parte, pueden discernirse desde hace ya varias décadas intentos de lograr la «suspensión de la incredulidad» y el mantenimiento de la illusio del lector con medios que huyen de una apuesta referencial. En el ámbito peninsular, la estrategia citada por Zaro fue utilizada, por ejemplo, en el caso de la versión catalana realizada por Rossend Arqués de la novela Ernesto de Umberto Saba publicada en 1987 por Edicions de La Magrana. El original de Saba contiene diálogos en la variante del italiano hablada en Trieste; y Arqués explica en su posfacio que no se atrevió a elegir la «solución límite» de traducir los diálogos al mallorquín, por ejemplo, porque ello le habría obligado a adaptar la obra y a convertir Trieste en Mallorca. En vez de eso, lo que hizo fue crear una especie de «pancatalán», un dialecto artificial hecho de palabras y expresiones de las diferentes variantes del catalán, cuidando sobre todo de no caer en un tono excesivamente rural puesto que la novela está localizada en un ambiente urbano. Arqués admite la artificialidad de su invento en contraste con lo natural del habla triestina del original (que tiene en la obra la función de trasladar la pureza y la inocencia del personaje), pero concluye que su opción le parece la más «justa» $y$, al argumento de la pérdida de la belleza con respecto al original, responde remitiendo al lector directamente al texto italiano.

Al hilo de esas reflexiones, quisiera ofrecer a continuación algunos ejemplos extraídos de dos de las diversas obras en las que he tenido que abordar la traducción de lenguajes culturalmente marcados o de lenguajes en los que la distor- 
sión debida a factores culturales específicos es muy fuerte. He ampliado, pues, algunas notas recopiladas a lo largo de los años para diversas charlas y que permanecían olvidadas en algunos sectores del disco duro de mi ordenador. Creo que el tipo de solución adoptado permite esquivar, al menos en parte, el escollo de la localización excesiva y puede contribuir con ello a diluir las incomodidades transatlánticas. Al mismo tiempo, ofrece una solución autónoma en términos literarios al espinoso problema de la traducción de la diversidad lingüística.

Sin embargo, antes quisiera hacer algunas consideraciones de carácter más amplio. Creo que debemos admitir que la traducción (la traducción, a secas) no ocupa lugar alguno en la percepción común de lo literario. La idea imperante entre críticos y lectores en general acerca de la traducción privilegia nociones como las de transparencia o invisibilidad y, en última instancia, puede resumirse en la frase «la mejor traducción es la que no lo parece». Esta frase es del teórico de la traducción Eugene Nida (I982: I2), aunque quizá sea más preciso referirse a él como un teórico de la evangelización, puesto que ése era su propósito último. Semejante afirmación puede traer a la mente otra frase del escritor Kurt Vonnegut: «Somos lo que aparentamos, así que debemos ser cuidadosos con lo que aparentamos». Parecer una traducción es malo, porque entonces eres una traducción, lo cual es algo malo. Nos encontramos encerrados en un bucle del que es imposible salir. Una «trampa-22», por utilizar la expresión de otro autor de culto, Joseph Heller. La trampa perfecta.

En el fondo, traducción y fracaso son percibidos en el imaginario común como sinónimos. Es como si de los artículos publicados hace poco más de sesenta años por Ortega y Gasset en el diario La Nación de Buenos Aires sólo se retuviera la primera palabra del título, «miseria»: la idea del traducir como «mera pretensión, vano proyecto y ademán inválido». Sin embargo, lo cierto es que, si bien Ortega se pregunta: «¿No es la traducción, sin remedio, un afán utópico?», acto seguido se responde: «Verdad es que cada día me acuesto más a la opinión de que lo que hace el hombre es utópico» (Ortega, I983 [1937]: 433). Ahora bien, da la impresión de que esa matización orteguiana es demasiado sutil, porque, si hemos que extraer una conclusión a partir de los comentarios generales y periodísticos, deduciremos que traducir es, sin remedio, una bellaquería.

Una parte esencial del problema radica en el modo en que concebimos la lectura de una obra y el modo en que no concebimos - y no queremos concebir - la traducción, una operación que arrastra esa carga infamante que tan bien refleja el mito de la torre de Babel (López Guix, 2007). La T de traducción es, en nuestro imaginario, una segunda marca de Caín que nos convierte en apestados, en seres condenados de nuevo a la errancia y al desprecio de los hombres. La lectura en traducción siempre carga el lenguaje con un añadido de sospecha. En el ámbito musical, uno de los ámbitos de comparación predilectos de Miguel Sáenz (Sáenz, 2013), la diversidad en lo interpretativo es percibida como una riqueza; sin embargo, en lo literario (en la lectura de una novela, por ejemplo), en modo alguno hay espacio para admitir que la traducción es lo que es: una lectura, una interpretación, fijada. Lo que se busca, por el contrario, es la comunión con lo Uno. Y a nadie le gusta comulgar y notar el gusto de la harina.

\section{LO UNO Y LO DIVERSO}

Si la presencia del traductor siempre resulta molesta, la incomodidad se multiplica, en caste1lano, cuando entra en juego el carácter ultrama- 
rino de la traducción. Esa incomodidad queda ilustrada por el historial de un peculiar apartado titulado «Críticas» en la entrada de la editorial Anagrama en Wikipedia. Presento diferentes estadios de su redacción a lo largo de un período de casi seis años (Wikipedia, 2008-20I4):

[3 abril 2008] La editorial y sus traductores han sido criticados por usar en las traducciones una cantidad excesiva de expresiones propias del castellano de España.

[4 abril 2008] La editorial y sus traductores han sido criticados por usar en las traducciones una cantidad excesiva de expresiones propias del castellano de España. Una respuesta posible es que el $75 \%$ de las ventas de la editorial se realiza en España, pero Jorge Herralde cree que cuando el original está escrito en coloquial es impensable optar por una traducción neutra. Lamentablemente el lector latinoamericano en lugar de imaginarse a un escocés o a un inglés se imagina a un madrileño.

[20 marzo 20I0] La editorial y sus traductores han sido criticados por usar en las traducciones una cantidad excesiva de expresiones propias del castellano de España. Una respuesta posible es que el $75 \%$ de las ventas de la editorial se realiza en España, pero Jorge Herralde cree que cuando el original está escrito en coloquial es impensable optar por una traducción neutra.

[I3 febrero 20I2] La editorial y sus traductores han sido criticados por usar en las traducciones una cantidad excesiva de expresiones propias del castellano de España. Una respuesta posible es que el $75 \%$ de las ventas de la editorial se realiza en España, pero Jorge Herralde cree que cuando el original está escrito en coloquial es impensable optar por una traducción neutra En Argentina, Matías Fernández ha creado la web participativa Ibe- riado, donde los lectores repertorian los españolismos que Anagrama y otras editoriales españolas sirven al mercado latinoamericano sin glosario alguno que ayude a interpretarlos.

[I4 febrero 20I4] La editorial y sus traductores han sido criticados por usar en las traducciones una cantidad excesiva de expresiones propias del castellano de España. Una respuesta posible es que el $75 \%$ de las ventas de la editorial se realiza en España, pero Jorge Herralde cree que cuando el original está escrito en coloquial es impensable optar por una traducción neutra.

Como se ve, el comentario irónico del 4 de abril del 2008 expresa el malestar hacia lo que se percibe de modo transatlántico como un «españolismos» excesivo de las traducciones. Tras la eliminación de la frase en el 20ro, un nuevo comentario en el mismo sentido volvió a aparecer en el 20I2, eliminado nuevamente en el 20I4. Las críticas acerca de una apropiación lingüística excesiva llevada a cabo por traductores que intentan trasladar localmente la variación lingüística me parecen justificadas en términos literarios. Sin embargo, los comentarios como los mencionados parecen propugnar simplemente el cambio de una localización por otra. ¿Se está pidiendo que el lector latinoamericano, para imaginar a un escocés o a un inglés, imagine a un "porteño» o a un «santiaguino» (y no un «madrileño», desde luego)? Si es así, la solución es fácil y sólo depende de la voluntad editorial de aceptar nuevos desembolsos con la esperanza de poder rentabilizarlos. Ahora bien, ¿̇no tenía que imaginar el lector a un escocés? Por otra parte, conociendo ciertas dinámicas empresariales, siempre se corre el peligro de que el resultado final, esas diferentes versiones particulares, no sean versiones autónomas y coherentes, sino compuestos artificiosos hechos de cortes, añadi- 
dos y sustituciones realizados sin control alguno y donde desaparezcan los delicados equilibrios estilísticos logrados por el traductor del original. Puede que me equivoque y no sea así: al fin y al cabo, las obras británicas, se «editan» para el mercado estadounidense; y los autores británicos, a pesar de sus protestas, suelen aceptar esas modificaciones si quieren acceder a la comercialización en los Estados Unidos. Es conocida la posición de J. K. Rowling en la defensa de la «britanidad» de su obra; sin embargo, acabó permitiendo algunos cambios léxicos que suponían una adaptación del inglés británico al inglés estadounidense (Woods, 2000). El ejemplo más notorio es el cambio de título en el primer libro de la serie, Harry Potter and the Philosopher's Stone (1997), que se convirtió en Harry Potter and the Sorcerer's Stone (1998) en los Estados Unidos, donde la referencia a la filosofía se juzgó demasiado perturbadora para las mentes infantiles y se transformó en una referencia a la brujería. Una decisión que la propia autora lamentó públicamente más tarde (Rowling, 200r). En cambio, se mantuvo firme en la decisión de que fueran actores británicos los que encarnaran a sus personajes en la pantalla (Bradshaw, 20or).

De un modo general, se considera que la traducción consiste en la búsqueda de equivalentes lo más «fieles» posibles. Esta pretendida búsqueda de la fidelidad se basa en el postulado de la identidad de los efectos. Se supone que la lectura de la traducción debe conseguir en sus lectores el mismo efecto que produce el original en sus lectores.

Sin embargo, este modelo muestra sus carencias cuando lo que está en juego es el propio lenguaje o elementos que son particulares de una cultura o incluso elementos procedentes de culturas diversas, lo cual es el caso cada vez más en la literatura de un mundo globalizado.
Si tomamos en consideración el inglés, vehículo de una literatura vastísima y nuestra principal lengua de partida por lo que hace a las obras publicadas en traducción, ¿dónde debemos medir el «efecto original» de las obras de Salman Rushdie? ¿En Londres, en Bombay o en algún otro lugar? Las teorías de la traducción que defienden la identidad de los efectos no parecen tener del todo en cuenta las teorías literarias que postulan el papel activo de los lectores (que no son idénticos) en la construcción del sentido.

A continuación presento muestras del modo en que resolví la traducción de dos originales con un lenguaje muy alejado de los usos convencionales, a veces apropiándome de elementos existentes en la multiplicidad lingüística del castellano, a veces inventándolos, pero siempre al servicio de la construcción de un artefacto literario coherente. Aunque sea aquí de un modo sucinto, puede resultar de interés este desvelamiento de los procedimientos que suelen permanecer ocultos en la cocina del traductor.

\section{BREVE DICCIONARIO CHINO-INGLÉS PARA ENAMORADOS}

En el 20io traduje para la editorial Bruguera un libro titulado Breve diccionario chino-inglés para enamorados de Xiaolu Guo, cineasta y escritora china en lengua inglesa (título original: $A$ Concise Chinese-English Dictionary for Lovers, Chatto \& Windus, 2007). Algunos años después, la traducción fue objeto de comentario por parte de África Vidal (20I4) en un artículo publicado en ElTrujamán unas semanas antes del mencionado texto de Zaro. También a ella se debe en parte que haya rescatado estas notas.

La obra, que recoge en parte las experiencias de la autora, que se estableció en Londres en el 2002, tiene la forma de un diario en el que 
una joven china cuenta su vida de estudiante de inglés en Londres. Está dividida en pequeños capítulos dedicados cada uno a una palabra o expresión inglesa, que se supone que la protagonista va aprendiendo. Y efectivamente es así, porque a medida que avanza la obra, el inglés va mejorando, desde una lengua inicial que es en realidad una tercera lengua, inglés en apariencia, pero completamente traspasada por las estructuras del chino. En realidad, se trata de una novela acerca de la traducción y acerca de la identidad en un mundo contemporáneo cada vez más entropizado. En ella se oponen dos fuerzas contrarias: la intensidad expresiva del lenguaje literario y el uso decidido de unos medios lingüísticos imperfectos que reflejan el choque y la extrañeza de una mirada exterior. Empieza así:

Now.

Beijing time I2 clock midnight,

London time 5 clock afternoon.

But I neither time zone. I on airplane. Sitting on $25,000 \mathrm{~km}$ above to earth and trying remember all English I learning in school.

I not met you yet. You in future.

Ahora.

Hora Pekín doce medianoche.

Hora Londres cinco tarde.

Pero yo en ninguna parte horaria. Yo en avión. Sienta en 25.000 kilómetros encima de tierra y quiere recuerda todo inglés aprendido en escuela.

Yo no encuentra tú todavía. Tú en futuro.

Y sigue:

In my text book I study back in China, it says English peoples talk like this:

'How are you?'

'I am very well. How are you?'

'I am very well.'
Question and answer exactly the same!

Old saying in China: 'Birds have they bird language, beasts have they beast talk' (鸟有鸟 语, 兽有兽言). English they totally another species.

(pp. 9-1о)

En libro de texto yo estudia antes en China, dice gentes ingleses habla así:

How are you?

I am very well. How are you?

I am very well.

¡Pregunta y respuesta exacto lo mismo!

Viejo refrán en China: «Pájaros habla lenguaje de pájaros, bestias habla palabra de bestias» (鸟有鸟语, 兽有兽言). Ingleses completamente otra especie.

(pp. 23-24)

La obra no se limita a reflejar la perplejidad de la protagonista; en esa interacción entre lo familiar y lo extraño, la visión desde lo ajeno (formal y culturalmente) permite arrojar - y lo hace con humor - una luz nueva sobre algunos aspectos de lo que consideramos propio. Podemos preguntarnos cuál es el equivalente castellano del defectuoso modo de hablar el inglés de la joven protagonista china, teniendo en cuenta además que en ese «choque de civilizaciones», no sólo se desconstruye la gramática del inglés, sino que se ponen en entredicho los fundamentos de una cultura específica.

El reto del traductor, como el de la autora, fue construir una riqueza de contenido mediante una catastrófica pobreza formal. La traducción intentó encontrar un equilibrio entre estos dos elementos opuestos y reproducir, desde la lógica del castellano, el sabotaje al que se ve sometida la propia narración en el intento de expresar con una gramática desestabilizada una confusión mucho más general. Para ello, fue conveniente en muchas ocasiones indagar en 
el substrato chino que condiciona el original inglés y además no olvidar en ningún momento que las culturas en conflicto eran la británica y la china. La palabra inglesa que titula cada capítulo funciona como lema de diccionario al que sigue su definición, a veces parcial, incorrecta o cómica. La mantuve en inglés, aunque traduje la definición. En ocasiones resultaba útil contar con el anglicismo dentro del texto. El segundo capítulo se titula «alien»:

Is unbelievable. I arriving London, 'Heathlow Airport'. Every single name very difficult remembering, because just not 'London Airport' we simple way call 'Beijing Airport'. Everything very confuse way here, passengers is separating in two queues.

Sign in front of queue say ALIEN and NON ALIEN.

I am alien, like Hollywood film Alien, I live in another planet, with funny looking and strange language.

Increíble. Yo llega Londres. Aeropuerto de Heathlow. Cada palabra muy difícil recordar, por qué no sencillo Aeropuerto de Londres como nosotros modo sencillo dice Aeropuerto de Pekín. Todo forma muy complicado aquí, pasajeros separa en dos colas.

Señal delante de cola dice: ALIEN y NON ALIEN.

Yo soy alien, como película Hollywood Alien, yo vive en otro planeta, con idioma extraño y aspecto raro.

El uso esporádico del inglés dentro del texto permitía reflejar mejor todo el proceso de aprendizaje de la protagonista y permitía resolver de modo más satisfactorio, creo, algunos problemas de traducción.
Una cosa, también Shakespeare escribe mal inglés. Por ejemplo, dice «Where go thou?». Si yo habla así señora Margaret me dirá malamente.

Hubo que encontrar el modo de introducir un progreso en la utilización de los tiempos verbales, un aspecto en el que, desde el punto de vista del castellano, el inglés no se diferencia tanto del chino, que sólo tiene una forma verbal (el infinitivo). De todos modos, se trataba de un asunto que desborda claramente a la protagonista.

Yo no entiende por qué verbo siempre puede cambiando.

$$
\text { (p. 40) }
$$

Según la progresión en el nivel de inglés de la protagonista, fui introduciendo la complejidad de los tiempos y formas verbales del castellano, a partir de un uso inicial de la tercera persona del presente del singular. Sólo utilicé el imperfecto de subjuntivo en contadas ocasiones y en la segunda parte de la novela. A medida que las desinencias verbales se volvían más gramaticales, fue posible gestionar mejor los sujetos pronominales y otros pronombres.

«Hablar no hervir arroz», dice chinos. Única cosa me importa en vida es comida. Y yo primero aprende inglés por comida, por supuesto. Es manera más práctica.

También tuve que encontrar un modo de introducir el género y el número de los adjetivos. En otros aspectos, el uso inadecuado de las preposiciones, por ejemplo, la plantilla proporcionada por el inglés ya servía. Como en el caso de la frase que antecede al diario: 
Sorry of my English.

272

Perdón de mi inglés.
Éstas son algunas de las dificultades que presentaba el libro y algunas de las formas en que intenté reproducir en castellano el choque entre la cultura británica y la china, utilizando como plantilla el inglés y recurriendo además a los medios expresivos del castellano. El problema era relativamente sencillo, puesto que, en el caso de esta obra, puede suponerse que el lector está dispuesto de entrada a aceptar una elevada dosis de agramaticalidad y, por parte del traductor, se trataba de mantener la coherencia y la progresión del método elegido. Para suplir mi completo desconocimiento del chino conté con la ayuda de una sinóloga, Maialen Marín, $y$, a la hora de apreciar su forma de influir en el castellano, con la ayuda nunca agradecida por mi parte, de las voces interiorizadas de los dueños del restaurante chino que a veces visito. Esas voces mentales me sirvieron en ocasiones para pensar si un rasgo o una frase sonaba «natural». Así que, en la fase del pulido de la traducción y para calibrar el modo en que sonaban algunas agramaticalidades, utilicé como pequeño filtro de veracidad una realidad lingüística análoga y realmente existente en la cultura de llegada. De todos modos, deseo insistir en que mi propósito principal no era trasladar esa realidad lingüística existente en castellano sino utilizar algunos de sus rasgos para insertarlos según mi conveniencia en la construcción de una obra literaria.

\section{TODO UN HOMBRE}

Un caso algo más complejo fue el de otra novela que traduje en 1999 para Ediciones B, Todo un hombre de Tom Wolfe (título original: $A$ Man in Full, Farrar, Straus \& Giroux, r998). Wolfe hace desfilar por sus páginas a unos doscientos personajes, una docena de ellos con modos de hablar claramente diferenciados y, en un principio, ininteligibles para la mayoría de los lectores anglófonos. Tanto es así que son objeto de comentario y explicación por parte de la voz narradora. De esa docena de formas de hablar características y existentes en la sociedad de los Estados Unidos, las que aparecen con mayor frecuencia son, por fortuna, sólo cuatro: el habla cracker (de los blancos pobres del Sur), el habla oky (de los blancos pobres de la zona de la bahía de San Francisco), la de los negros y la de un hawaiano apodado 5-Cero.

Ante una obra así, cabe preguntar: ¿cuál es el «equivalente» castellano del habla rústica de los blancos pobres de los condados de Georgia o del habla degradada de los negros o de los trabajadores blancos menos cualificados de la zona de Oakland? ¿Y del criollo hawaiano, una lengua basada en el inglés con influencia del hawaiano, pero también del chino, el japonés, el portugués y el filipino?

En la traducción de Todo un hombre, opté de forma sistemática por el abandono de la pretensión mimética y por la construcción de hablas coherentes, pero descartando toda remisión a un referente sociológico supuestamente equivalente y, desde luego, inexistente. Mi solución, de tipo literalista y que he descrito con más extensión en otro lugar (López Guix, 20o9), consistió en identificar los rasgos formales característicos de los usos lingüísticos que Wolfe reproducía de modo minucioso para luego, siguiendo esas pautas, crear unas hablas coherentes (como las del original), pero sin pretender en ningún momento lograr en el lector un reconocimiento de referentes lingüísticos conocidos, sólo una extrañeza ante unos usos no estándares del idioma. 
Para ello utilicé, de nuevo, la plantilla del inglés. Identifiqué los principales rasgos formales de esas voces e intenté reproducirlos en castellano. Para el habla craker, pues, recurrí de modo abundante a transformaciones morfológicas como apócopes (quie por «quiere»; de tos mos por «de todos modos»), aféresis (migo por «amigo»), síncopas (captán por «capitán») o metátesis (termtina por «trementina»), así como a diversas combinaciones de esos y otros procedimientos que daban lugar, en ocasiones, a resegmentaciones de las palabras (cicli mobiliario por «ciclo inmobiliario»; locharon por «lo echaron»; cay por «qué hay»), lo cual ocurría también en el inglés con efectos visuales muy llamativos. En el nivel sintáctico, utilicé un sistema verbal defectuoso, sin algunos tiempos verbales y utilizando mal otros, así como construcciones incorrectas de los pronombres proclíticos, la omisión de palabras, los pleonasmos, la alteración del orden de las palabras o el anacoluto. Tomadas de modo individual, algunas de estas modificaciones aparecen en los usos de algunos hablantes del castellano, porque siguen cierta lógica intrínseca del idioma, pero tomadas globalmente carecen de correlato en nuestra realidad lingüística.

Para el habla de los negros, recurrí también a modificaciones morfológicas, pero adquirieron más importancia los rasgos de tipo sintáctico: un empleo peculiar de las negaciones (tratando de reutilizar de algún modo el uso subestándar de la negación múltiple («No one never said nothing» en lugar de "No one ever said anything»; por ejemplo, en «Nos mi intención ni insultarte y nos mi intención ni jugártela»), redundancias (con los pronombres, por ejemplo) y repeticiones que confieren al discurso un ritmo particular. En el nivel léxico abundaban ciertas palabras malsonantes y las palabras identificadas en el propio texto como «negras».
E1 habla oky se caracteriza, entre otras cosas, por una frecuencia aún más elevada de palabras malsonantes, así como por la utilización de una gran cantidad de argot. La dificultad, como siempre en estos casos, reside en que el registro lingüístico jergal posee una fuerte marca diatópica. Intenté diluir el problema recurriendo a palabras de distintas procedencias geográficas (de México, por ejemplo), sacadas de glosarios de Internet.

El habla más compleja era el pidgin hawaiano, mezcla de media docena de lenguas mencionada más arriba. Además de un vocabulario propio, presenta unos rasgos sintácticos muy marcados y coherentes. En la traducción, tendí a conservar las palabras no procedentes del inglés (hawaianas, principalmente), con objeto de obtener una nota de color. Utilicé también diversas transformaciones morfológicas y léxicas. Las palabras modificadas a partir del inglés, sufrían cambios similares (spabk por saminar). Otro elemento distintivo era la gran frecuencia de la letra $d$ que aparecía debida una simplificación fonética de la oclusiva alveolar sonora $/ \mathrm{d} /$ y la fricativa dental sorda $/ \theta /$ (the, that). Arbitrariamente, añadí esta letra a algunos pronombres y artículos, principalmente (dellos, dese, desos, da, deseguida, da veras). Hubo otras grandes transformaciones de carácter sintáctico y gramatical. Por ejemplo, el sistema verbal de esa habla es bastante básico y utiliza partículas antepuestas para indicar el pasado y el futuro (wen y going, respectivamente). Para lo primero, pensé en imitar el recurso utilizando «antes» antepuesto al verbo, pero en mi búsqueda en diversas obras de lingüística descubrí a tiempo que el chabacano - un criollo hablado en Filipinas, mezcla de español, tagalo y otras lenguas locales - utiliza el adverbio «ya» para indicar el pasado («ya pensa le baña antes de bolber na kasa»). Encontré ese dato en la ver- 
sión castellana de la Enciclopedia del lenguaje de David Crystal (I994), una obra que también me facilitó la solución para la traducción del futuro, pues ofrece ejemplos de un pidgin hablado en la parte occidental de Venezuela, mezcla de español y panare, que se llama español piñaguero panare y que recurre al gerundio para indicar el futuro. Así, por ejemplo, «tendrás que pagar mucho» o «te daré mucho» se dirían «tú pagando mucho fuerte» $\mathrm{y}$ "yo dando mucho fuerte». Además, para compensar algunas repeticiones $\mathrm{y}$ trasposiciones muy frecuentes, introduje un gran cambio estructural y decidí cambiar el orden básico de los elementos de la frase (svo: $75 \%$ lenguas del mundo) y utilizar el orden vso (presente sólo en un Iо\%) («matando dellos ti»; es decir, «te matarán»). Como dato curioso en relación con la alteración del orden sintáctico, cabe señalar que este tipo de procedimiento cuyo objetivo es conseguir un poderoso efecto de extrañamiento se utilizó en el habla del Yoda de la saga La guerra de las galaxias, quien utiliza el orden osv, casi inexistente entre las lenguas del mundo.

Las respuestas, por parte de críticos y lectores comunes, a este proceder fueron de dos tipos. Por un lado, de irritación por el «exceso de originalidad» del traductor en la traducción de unas «expresiones intraducibles», en palabras de un crítico, escritor peruano afincado en Sevilla (Iwasaki, I999). Un lector de Bilbao me escribió una carta muy cortés, pero en la que me preguntaba por qué no me limitaba a «traducir y punto». (Aunque en el curso de nuestra correspondencia - espero que por convencimiento, no por cortesía ni cansancio- acabó considerando equivocado «buscar referentes equivalentes en el segundo idioma».) Una lectora de Madrid, envió una airada carta a El País, donde decía que Wolfe empleaba «muchas expresiones profundamente americanas» y añadía «la traducción merece hacerse con cuidado, no sólo para que refleje lo mejor posible lo que él relata, sino para no ayudar a destrozar la lengua española» (Benito, I999). Dejando de lado, el detalle de que creo que en ese caso «destrozar la lengua española» era un elogio, estas reacciones muestran la concepción habitual de la traducción como simple reflejo especular del original. Una concepción que exige «traducir y punto» para «reflejar lo mejor posible» unas «expresiones intraducibles». Muestran también el enfado de algunos lectores ante el abandono, por parte del traductor, de su papel tradicionalmente asignado, el de supuesto espejo. En realidad, el traductor siempre actúa como máscara, reconocida o no; como personaje que modula o templa voces, por más que se prefiera no verlo así. En realidad, cuando se le pide que actúe como espejo muchas veces se le está pidiendo que obre de tal modo que refleje al que mira.

Por fortuna, no todo fueron críticas y enojos, sino que la traducción de Todo un hombre, con su intento de huir de los localismos excesivos y de buscar una base lingüística más amplia, también tuvo aceptación entre los lectores. El prestigioso crítico Eduardo Haro Tecglen calificó el trabajo de «esmerado» y lo alabó en El País: «La dificultad de este excelente libro me hubiera hecho retroceder: el recurso de su traductor lo sitúa en el gran lugar debido» (Haro, I999). Y también recibí algunos correos de hispanohablantes no peninsulares receptivos a mi propuesta. Un periodista y escritor mexicano (Dorantes, I999) me envió su reseña para el periódico El Economista donde se elogiaba la traducción de un modo a todas luces desmesurado, pero que me sirve como ejemplo de aceptación ultrapeninsular («Es difícil pensar en una novela de habla inglesa mejor traducida al castellano que ésta»); $y$, por mencionar un último ejemplo de otra procedencia geográfica, una lectora argentina 
con muchos años de residencia en España me escribió comentando que le parecía que «utilizaba palabras de uso no demasiado corriente en España pero sí en Argentina».

\section{CONCLUSIÓN}

Creo que podemos subscribir la opinión de Jorge Herralde, fundador de Anagrama, sobre la conveniencia de no neutralizar los lenguajes marcados. Sin embargo, la solución en la que primero se piensa es la de trasladar la marca local original por otra marca que muchos percibimos como excesivamente localista. Se trata de una solución que, a mi entender, no es del todo satisfactoria en términos literarios. Comparto la incomodidad ante la lectura de esas traducciones que para imaginar a un «inglés» nos piden que imaginemos a un «madrileño», de modo que me inclino en esos casos por buscar anomalías del habla (ya sea en el plano léxico o en el plano sintáctico) recurriendo a opciones (inventadas o no) en las que prime cierto grado de extrañeza con respecto al uso estándar, pero evitando en la medida de mis posibilidades opciones marcadamente localizadoras. Evidentemente, algunas elecciones léxicas son inevitables, pero creo que se puede hacer un esfuerzo para que interfieran lo menos posible en el ritmo y la fluidez generales.

Soy consciente de las dificultades de la propuesta. Dejando de lado la pericia o la suerte del traductor, deben tenerse también en cuenta la inercia de los lectores, la escasa presencia de una tradición literaria consolidada ante el problema de la variación lingüística en traducción o el temor de los editores ante experimentos demasiado osados. Todos estos factores refuerzan la dinámica general que lleva a la realización de traducciones múltiples o a la estrategia —más barata - de retocar una traducción para adap- tarla al correspondiente mercado local. En última instancia, no hay que olvidar que las pautas que condicionan la lectura no aceptan con facilidad que el traductor se haga demasiado visible; $y$, como en el cuento de Borges acerca de espejos y máscaras, quizá su destino sea siempre recibir una daga, y morir apuñalado.

\section{REFERENCIAS}

Benito, A. (1999). «Carta al director», en El País Semanal, I7 octubre 1999.

Bradshaw, P. (20or). "Harry Potter and the Philosopher's Stone», The Guardian, 16 noviembre 200I, <http://www.theguardian.com/film/200I/ nov/r6/jkjoannekathleenrowling>. [Consulta: 28 julio 20I4]

Crystal, D. (1994). Enciclopedia del lenguaje de la Universidad de Cambridge, ed. Juan Carlos Moreno Cabrera, Madrid: Taurus.

Dorantes, J. (I999). «Todo un hombre: la obra maestra de Tom Wolfe», El Economista, 5 noviembre I999.

Guo, X. (2007). A Concise Chinese-English Dictionary for Lovers, Londres: Chatto \& Windus.

- (2010). Breve diccionario chino-inglés para enamorados, trad. Juan Gabriel López Guix, Barcelona: Bruguera.

Haro Tecglen, E. (1999). «Traducir a Tom Wolfe», Babelia, 9 octubre 1999.

Iwasaki, F. (I999). «Wolfe a la hoguera», Renacimiento, 25-26 (invierno I999).

López Guix, J. G. (2009). «Los lenguajes de la ficción», en Escrituras de la traducción hispánica, Valdivia: Universidad Austral de Chile-Kultrún. pp. I49-165.

- (2007). «Tras la sombra de Babel», I6II, I, <http:// www.traduccionliteraria.org/I6rI/art/lopezguix. htm>. [Consulta: 28 julio 20I4]

Nida, E., y C. Taber (1982). The Theory and Practice of Translation, Leiden: United Bible SocietiesBrill.

Ortega y Gasset, J. (1983). «Esplendor y miseria de la traducción» (1937), en Obras completas, vol. 5, Madrid: Alianza, p. 433.

Rowling, J. K. (200I). Entrevista Red Nose Day Chat, BBC Online, I2 marzo 2001, <http://www.

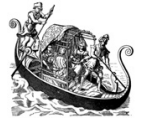

275 
accio-quote.org/articles/200I/o3Or-bbc-rednose. $\mathrm{htm}>$. [Consulta: 28 julio 20I4]

Sáenz, M. (2013). «El castellano bien templado», en Traducción. Dieciocho conferencias nada magistrales $y$ dos discursos de circunstancias, Salamanca: Ediciones Universidad de Salamanca, pp. 93-Io6.

Vidal, Á. (20I4). «Un diccionario chino para amar (brevemente) en inglés», El Trujamán, 30 junio 20I4, <http://cvc.cervantes.es/trujaman/anteriores/junio_I4/300620I4.htm> [Consulta: 30 junio 20I4]

Wikipedia (2008-20I4). «Editorial Anagrama»,
$<$ http://es.wikipedia.org/wiki/Editorial_Anagrama>. [Consulta: 28 julio 20I4]

Wolfe, T. (1998). A Man in Full, Nueva York: Farrar, Straus \& Giroux.

- (I999). Todo un hombre, trad. Juan Gabriel López Guix, Barcelona: B.

Woods, A. (2000), «Success Stuns Harry Potter Author», Associated Press, 6 julio 2000.

Zaro, J. J. (20I4). «¿Un español midatlántico?», El Trujamán, 2I julio 20I4, <http://cvc.cervantes. es/trujaman/anteriores/julio_I4/210720I4.htm>. [Consulta: 2I julio 20I4] 